\title{
A Study of Shark Stealth Behavior in the Proximity of Divers
}

\author{
Erich Ritter1,2, Raid Amin1 \\ ${ }^{1}$ Department of Mathematics and Statistics, University of West Florida, Pensacola, USA \\ ${ }^{2}$ Shark Research Institute Florida Office, Pensacola, USA \\ Email: erichritter@att.net
}

Received 25 February 2015; accepted 27 April 2015; published 4 May 2015

Copyright (C) 2015 by authors and Scientific Research Publishing Inc.

This work is licensed under the Creative Commons Attribution International License (CC BY). http://creativecommons.org/licenses/by/4.0/

(c) ()

\begin{abstract}
This study examines the approach patterns of sharks in the vicinity of human divers, focusing on the diver's body orientation and a shark's distance from the sea bed when approaching the diver. A standardized video method was used to record the scenario of diver(s) kneeling in the sand while being approached by sharks. This showed that sharks had a preference to move in from outside a diver's field of vision while larger sharks stayed closer to the sea floor. This may simultaneously enhance camouflage while reducing potential escape routes for the approaching animal. This stealth behavior raises the question of how sharks may interpret humans when moving towards them.
\end{abstract}

Keywords

Blind Spot, Camouflage, Escape Routes, Shark, Stealth

\section{Introduction}

It is known that sharks have the ability to determine human body orientation [1]. We previously showed that given the opportunity, significantly more Caribbean reef sharks (Carcharhinus perezi) approached a person from outside his or her field of vision - in the diver's blind spot area - rather than from inside their visual field $(\mathrm{p}<0.0001)$ [1]. In addition to determining the general direction of its approach, a shark also chooses a minimal approach distance, at which it turns away from the diver. This minimal approach distance likely indicates some kind of a personal sphere. This space has previously been described as the shark's idiosphere or inner circle, and ranges between 1.0 and 2.0 body lengths [2]-[4]. This distance may be equal to the flight initiation distance [5][7], and may also be comparable to the border of the near-field water pressure detection in teleosts [8]-[10].

In our initial study on approach patterns [1], we evaluated the preference of sharks to approach from either in- 
side or outside the diver's field of vision. For standardization, we focused on sharks that swam just off the sea floor when approaching the kneeling test subject and ignored the sharks approaching from farther off the bottom [1]. A greater distance from the sea floor offers more freedom of motion for an approaching shark, and provides a greater number of escape routes. On the other hand, swimming farther from the bottom, or higher in the water column, likely makes a shark more visible due to the lighter background. Thus, a balance between potential escape routes and visibility might manifest itself in a shark's chosen swim path.

The distance a shark chooses from the sea floor when approaching an object has not yet been quantitatively established. Therefore, this was the main focus of this study, to provide more insight into the concept of a shark's idiosphere [1]. Furthermore, the question is discussed how sharks may categorize an unfamiliar object-a human being - when in close range of it.

\section{Materials and Methods}

This study was conducted in November 2012, four years after our initial data was collected [1]. Besides using the same shark species, the Caribbean reef shark, we also used the same location in the Bahamas, consisting of a site with a sandy bottom, surrounded by coral reefs, and with an average water depth of $11 \mathrm{~m}$. We used the same general setup as previously described [1], but added more cameras to better evaluate a shark's distance from the sea floor. In total, we operated four cameras: three were positioned on the sea floor in a triangle formation with each corner $10 \mathrm{~m}$ from the center, where the test subject(s) were positioned; the fourth camera was positioned 10 $\mathrm{m}$ above the center of the triangle, held by a videographer.

Due to their possible interference with low swimming sharks, distributing vertical markers throughout the recording area was not feasible. Instead, a single stick of $2 \mathrm{~m}$ length was held in a vertical orientation by a testsubject to measure the approximate distance of a shark from the sea floor. This allowed estimation of the shark's position relative to the vertical marker as seen from the different camera angles rounded to the nearest $50 \mathrm{~cm}$. Since we tallied only those sharks that swam within $5 \mathrm{~m}$ of the center of the recording area, the calculated approximation appeared sufficiently accurate.

In contrast, because horizontal markers were not expected to affect the swim patterns of the sharks, these were spread throughout the recording area and all horizontal measurements (shark's body length, absolute distance from the diver, and relative distance from the diver, expressed as a fraction of a shark's body length) were directly measured from the markers in the video clips using Pixelstick 2.3 (Plum Amazing) and rounded to the nearest $10 \mathrm{~cm}$. Video evaluation was performed with either iMovie 8.0 (Apple ${ }^{\circledR}$ ) or, if enhancements were needed for clarification, with Final Cut Pro X (Apple®).

To quantify a shark's approach direction, diver positions in both single and double-diver setups, followed our initial method [1]. In the single-diver setup, the diver was in a kneeling position in the center of the recording area looking in one direction, marked as the $0^{\circ}$ line. The diver's visual field was then defined as the $90^{\circ}$ sector to the left and right of this line. The corresponding $180^{\circ}$ line, together with the two $90^{\circ}$ sectors to either side was defined as the blind-spot area. Every shark was then tallied based on whether it approached in the diver's visual field or blind-spot area, in addition to all the measurements previously mentioned. In the double-diver setup, a second diver was positioned back to back with the first person, looking along the $180^{\circ}$ line, thus eliminating the blind-spot area completely. In this case, the general approach areas of incoming sharks were still tallied with reference to the first diver's position. In order to ensure the results were not influenced by factors other than the orientation of the diver, the initial viewing direction of the test-subject and the center of the setup were changed for every test. Each test subject, chosen out of a pool of four divers, wore the same general outfit to minimize visual differences. Each test lasted 60 minutes, included both a single-diver and double-diver setups, taken back to back, for 30 minutes each.

Since meteorological circumstances are known to affect the behavior of sharks [11]-[13], we kept controllable factors similar by selecting the same time of day, sky conditions, and minimum underwater visibility. Safety procedures for humans among sharks were followed as described in our previously established risk assessment [1].

Because four years passed between our first study and this current work, it is a reasonable assumption that none of the sharks examined in the first study were still present in the area. As in our initial study, we did not tag sharks. We surmised that tagging is likely to alter shark behavior, since an animal must first be lured in close enough to apply a tag by spear gun or harpoon, or be caught by hook. Any of these procedures creates distress and pain among the animals [14]-[16]. Thus, it is likely that such a procedure would influence the later behavior 
of tagged sharks in the vicinity of a human being. Tagging would also not have been feasible, since any new and not previously tagged sharks would need to be ignored, or a subsequent capture attempted.

\section{Results}

During the course of this study, 201 encounters of sharks with divers were tallied. Significantly more sharks approached from the diver's blind side than from within his or her field of vision $(p=0.0003, n=75)$. With a double-diver setup, thus eliminating the actual blind side, the distribution of approaching sharks was non-significant $(\mathrm{p}>0.05, \mathrm{n}=126)$. Table 1 shows average lengths of sharks and closest relative distances to diver(s) for both setups. For comparison purposes, the corresponding data of the first evaluation [1] are also mentioned.

Slightly more than $41 \%$ of the sharks swam farther than $1 \mathrm{~m}$ off the sea floor when approaching the test-subject(s). However, larger sharks preferred to remain closer to the bottom than smaller sharks $(p<0.0001)$, independent of whether they moved in from the front or the back of a test subject.

\section{Discussion}

In order to assess the influence of diver position on shark behavior, we measured the orientation of a shark approaching a diver relative to the diver's field of vision and its height above the sea floor when approaching. In agreement with our previous study [1], given the chance of freely approaching a single diver, significantly more sharks approached from the diver's blind side than from his or her field of vision, indicating that sharks were able to detect human body orientation, as was already known for other animals [17]-[20]. It remains unclear how sharks are able to determine a diver's body orientation [1]. Since nearly $59 \%$ prefer to swim very near-less than $1 \mathrm{~m}$ - from the sea floor when approaching the test-subjects, we suggest that the ocean floor is used as a form of camouflage, allowing the sharks to better blend in, whereas a mid-water approach may make them more visible against the lighter background, illuminated by the sky [21]. Approaching close to the bottom to reduce visibility reflects a typical stealth behavior [22] [23]. Such an observation could imply that sharks might categorize humans as a potential form of prey. However, if the shark's idiosphere does indeed reflect a flight initiation distance [5]-[7], then humans can rather be categorized as some form of predator. Nevertheless, there is also the possibility that sharks assume humans to be neither a prey nor a predator and simply accept them as unfamiliar objects. It, therefore, remains unclear whether and how humans are categorized by sharks, but considering the low yearly incident rates between sharks and humans [24], there must be some factors that hold sharks back from biting more frequently during encounters with humans. Interpreting humans as something unfamiliar can reflect why the majority of bites that occur throughout the year are of an exploratory nature [25] [26], and thus the sharks may be attempting to find out what humans are. This suggests that a shark may not categorize the human as either a prey or a predator. However, it is also possible that some sharks assume one over the other, and that biting a person will then confirm or reject this assumption. Although this supposition seems plausible for sharks approaching from the blind side of a diver, it is less likely the case for sharks moving in from the front, because if the unfamiliar object reflects a potential predator, this will put an incoming shark in danger due to reduced availability of escape routes.

Table 1. Average lengths of sharks and closest distances, expressed in fraction of body length, before turning away from a diver.

\begin{tabular}{cccccccc}
\hline $\mathrm{N}_{\mathrm{d}}$ & $\mathrm{N}$ & $\mathrm{L}_{\mathrm{fo}} \pm \mathrm{SE}$ & $\mathrm{D}_{\mathrm{f}} \pm \mathrm{SE}$ & $\mathrm{N}$ & $\mathrm{L}_{\mathrm{b} \text { }} \pm \mathrm{SE}$ & $\mathrm{D}_{\mathrm{b}} \pm \mathrm{SE}$ & Reference \\
\hline 1 & 22 & $205.5 \pm 4.90$ & $1.7 \pm 0.10$ & 53 & $208.9 \pm 2.90$ & $1.5 \pm 0.06$ & Current study \\
2 & 53 & $212.1 \pm 2.60$ & $1.5 \pm 0.06$ & 73 & $210.4 \pm 2.30$ & $1.4 \pm 0.06$ & Current study \\
1 & 37 & $195.8 \pm 3.90$ & $1.9 \pm 0.04$ & 174 & $206.0 \pm 1.90$ & $1.9 \pm 0.08$ & Ritter and Amin, 2012 \\
2 & 45 & $203.1 \pm 3.80$ & $1.7 \pm 0.50$ & 56 & $202.8 \pm 2.60$ & $2.0 \pm 0.01$ & Ritter and Amin, 2012 \\
\hline
\end{tabular}

"Some data needed to be reevaluated to make them comparable with the current study; Note: $N_{d}=$ Number of divers; $N=$ Number of shark approaches; $\mathrm{L}_{f ø}=$ Average length of sharks approaching from the front; $\mathrm{D}_{\mathrm{f}}=$ Closest relative distance of sharks approaching from the front before turning away; $\mathrm{L}_{\mathrm{b} ø}$ $=$ Average length of sharks approaching from the back; $\mathrm{D}_{\mathrm{b}}=$ Closest relative distance of sharks approaching from the back before turning away. 
At this point, a definitive answer to the question of how sharks may interpret humans is not possible and it can't be ruled out that different shark species, or even individuals within a species, likely have different attitudes toward divers, using contrasting ways of thinking. So, what might be seen as a potential prey for one shark might reflect a potential predator for another one.

A better understanding is needed how sharks interpret divers. Since sharks show learning behavior during such encounters, their understanding may alter and their assumptions shift from one category to another. Thus, in the future studies, animals may need to be singled out and their swim patterns in the vicinity of a diver observed for longer periods of time.

Approaching a person is a complex decision-making process for sharks, in which assumptions have to be made once a shark is in a visible range of the diver. This demands the ability to weigh several factors against each other and proceed with the best possible assumption under the given circumstances.

\section{Acknowledgements}

We thank the test-subjects for their efforts, which made this project possible.

\section{References}

[1] Ritter, E.K. and Amin, R. (2014) Are Caribbean Reef Sharks, Carcharhinus perezi, Able to Perceive Human Body Orientation? Animal Cognition, 17, 745-753. http://dx.doi.org/10.1007/s10071-013-0706-z

[2] Ritter, E. and Amin, R. (2012) Effect of Human Body Position on the Swimming Behavior of Bull Sharks, Carcharhinus leucas. Society \& Animals, 20, 225-235. http://dx.doi.org/10.1163/15685306-12341235

[3] Ritter, E.K. (2006) Understanding Sharks: The Fascinating Behavior of a Threatened Hunter. Krieger, Melbourne.

[4] Martin, R.A. (2007) A Review of Shark Agonistic Displays: Comparison of Display Features and Implications for Shark-Human Interactions. Marine and Freshwater Behaviour and Physiology, 40, 3-34. http://dx.doi.org/10.1080/10236240601154872

[5] Frid, A. and Dill, L. (2002) Human-Caused Disturbance Stimuli as a Form of Predation Risk. Conservation Ecology, 6, 11. http://www.consecol.org/vol6/iss1/art11.

[6] Stankowich, T. and Blumstein, D.T. (2005) Fear in Animals: A Meta-Analysis and Review of Risk Management. Proceedings of the Royal Society, 272, 2627-2634. http://dx.doi.org/10.1098/rspb.2005.3251

[7] Cooper, W.E. and Frederick, W.G. (2007) Optimal Flight Initiation Distance. Journal of Theoretical Biology, 244, 5967. http://dx.doi.org/10.1016/j.jtbi.2006.07.011

[8] Bleekmann, H. (1986) Role of the Lateral Line in Fish Behaviour. In: Pitcher, T.J. Ed., The Behaviour of Teleost Fishes, Chapman \& Hall, London, 177-202. http://dx.doi.org/10.1007/978-1-4684-8261-4_ 7

[9] Sand, O., Enger, P.S., Karlsen, H.E. and Kudsen, F.R. (2001) Detection of Infrasound in Fish and Behavioral Responses to Intense Infrasound in Juvenile Salmonids and European Silver Eels: A Minireview. American Fisheries Society Symposium, 26, 183-193.

[10] Goulet, J., Engelmann, J., Chagnaud, B.P., Franosch, J.P., Suttner, J. and vanHemmen, L. (2008) Object Localization through the Lateral Line System of Fish: Theory and Experiment. Journal of Comparative Physiology A, 194, 1-17. http://dx.doi.org/10.1007/s00359-007-0275-1

[11] Heupel, M.R., Simpfendorfer, C.A. and Hueter, R.E. (2003) Running Before the Storm: Blacktip Sharks Respond to Falling Barometric Pressure Associated with Tropical Storm Gabrielle. Journal of Fish Biology, 63, 1357-1363. http://dx.doi.org/10.1046/j.1095-8649.2003.00250.x

[12] Towner, A.V., Underhill, L.G., Jewell, O.J.D. and Smale, M.J. (2013) Environmental Influences on the Abundance and Sexual Composition of White Sharks Carcharodon carcharias in Gansbaai, South Africa. PLoS ONE, 8, e71197. http://dx.doi.org/10.1371/journal.pone.0071197

[13] Amin, R., Ritter, E. and Wetzel, A. (2014) An Estimation of Shark-Attack Risk for the North and South Carolina Coastline. Journal of Coastal Research, in Press. http://dx.doi.org/10.2112/JCOASTRES-D-14-00027.1

[14] Chandroo, K.P., Duncan, I.J.H. and Moccia, R.D. (2004) Can Fish Suffer? Perspectives on Sentience, Pain, Fear and Stress. Applied Animal Behavior Science, 86, 225-250. http://dx.doi.org/10.1016/j.applanim.2004.02.004

[15] Huntingford, F.A., Adams, C., Braithwaite, V.A., Kadri, S., Pottinger, T.G., Sandøe, P. and Turnbull, J.F. (2006) Current Issues in Fish Welfare. Journal of Fish Biology, 68, 332-372. http://dx.doi.org/10.1111/j.0022-1112.2006.001046.x

[16] Braithwaite, V.A. and Boulcott, P. (2007) Pain Perception, Aversion and Fear in Fish. Diseases of Aquatic Organisms, 
75, 131-138. http://dx.doi.org/10.3354/dao075131

[17] Hampton, R.R. (1994) Sensitivity to Information Specifying the Line of Gaze of Humans in Sparrows (Passer domesticus). Behaviour, 130, 41-51. http://dx.doi.org/10.1163/156853994X00136

[18] Hare, B. and Tomasello, M. (1999) Domestic Dogs (Canis familiaris) Use Human and Conspecific Social Cues to Locate Hidden Food. Journal of Comparative Psychology, 113, 173-177. http://dx.doi.org/10.1037/0735-7036.113.2.173

[19] Pack, A.A. and Herman, L.M. (2004) Bottlenosed Dolphins (Tursiops truncatus) Comprehend the Referent of Both Static and Dynamic Human Gazing and Pointing in an Object-Choice Task. Journal of Comparative Psychology, 118, 160-171. http://dx.doi.org/10.1037/0735-7036.118.2.160

[20] Schloegl, C., Kotrschal, K. and Bugnyar, T. (2008) Do Common Ravens (Corvus corax) Rely on Human or Conspecific Gaze Cues to Detect Hidden Food? Animal Cognition, 11, 231-241. http://dx.doi.org/10.1007/s10071-007-0105-4

[21] Strong, W. (1996) Shape Discrimination and Visual Predatory Tactics in White Sharks. In: Klimley, A.P. and Ainley, D.G., Eds., Great White Sharks: The Biology of Carcharodon carcharias, Academic Press, London, 229-240. http://dx.doi.org/10.1016/B978-012415031-7/50022-7

[22] Heithaus, M.R., Dill, L.M., Marshall, G.J. and Buhleier, B. (2002) Habitat Use and Foraging Behavior of Tiger Sharks (Galeocerdo cuvier) in a Seagrass Ecosystem. Marine Biology, 140, 237-248. http://dx.doi.org/10.1007/s00227-001-0711-7

[23] Hulbert, L.B., Sigler, M.F. and Lunsford, C.R. (2006) Depth and Movement Behavior of the Pacific Sleeper Shark in the North-East Pacific Ocean. Journal of Fish Biology, 69, 406-425. http://dx.doi.org/10.1111/j.1095-8649.2006.01175.x

[24] Shark Research Institute (2015) Global Shark Attack File. Incident Log. http://www.sharkattackfile.net

[25] Ritter, E.K. and Levine, M. (2005) Bite Motivation of Sharks Reflected by the Wound Structure on Humans. Journal of Forensic Medicine and Pathology, 26, 136-140.

[26] Ritter, E. and Levine, M. (2004) Use of Forensic Analysis to Better Understand Shark Attack Behavior. Journal of Forensic Odonto-Stomatology, 22, 40-46. 